\title{
INTRODUCTION
}

\section{Cancer Survivorship Care for the General Internist: Have We Paved the Way for a Smoother Transition?}

\author{
Larissa Nekhlyudov, MD, MPH ${ }^{1,2}$ and Sheldon Greenfield, $\mathrm{MD}^{3}$ \\ 'Department of Population Medicine, Harvard Medical School, Boston, MA, USA; ${ }^{2}$ Department of Medicine, Harvard Vanguard Medical \\ Associates, Boston, MA, USA; ${ }^{3}$ Health Policy Research Institute, University of California, Irvine, CA, USA.
}

J Gen Intern Med 24(Suppl 2):381-2

DOI: $10.1007 / \mathrm{s} 11606-009-1088-4$

(c) Society of General Internal Medicine 2009

$\mathrm{U}$ ntil the last decade, "cancer survivorship" was a term used by few and there was little research and essentially no medical education efforts focused on this field. However, the landscape of cancer survivorship changed with the creation of the Office for Cancer Survivorship at the National Cancer Institute which led to research funding, the launch of the Lance Armstrong Foundation which promoted awareness of cancer survivorship in the public arena, and the publication of the Institute of Medicine report, "From Cancer Patient to Cancer Survivor: Lost in Transition" which solidified cancer survivorship as a distinct phase of cancer within the scientific and medical communities. ${ }^{1}$ While the population of cancer survivors is growing, aging, and has co-morbid medical conditions, there has been inadequate focus on cancer survivorship in general medicine research, education and clinical practice.

Whether a patient has congestive heart failure, diabetes or asthma, general internists are trained to provide comprehensive care to patients with complex medical conditions. ${ }^{2}$ While most cancer survivors eventually transition from active care provided by cancer specialists to long-term management by general internists, there are essentially no medical education or residency training curricula focusing on cancer survivorship. In prior studies, primary care providers expressed an interest in caring for cancer survivors, ${ }^{3}$ but only about half reported being comfortable in having responsibility for surveillance of cancer recurrences. ${ }^{4}$ This is consistent with studies showing that patients followed by primary care providers received more preventive care than those seen by oncologists and those followed by oncologists got more cancer surveillance than preventive care. ${ }^{5,6}$ The discrepancy between preventive care and cancer surveillance becomes more pronounced as survivors transition from oncology to primary care settings. ${ }^{7,8}$ When it comes to the management co-morbidities, the ball is often dropped. ${ }^{9}$ Moreover, it is becoming increasingly apparent that many long-term survivors experience health consequences from their treatment, decades later, when patients may no longer be seen in cancer settings. A comprehensive approach to cancer survivorship care, including coordination and clear communication between patients, oncologists and primary care providers is needed. ${ }^{10,11}$

The Institute of Medicine Report outlined several recommendations that are relevant to general internists. First, we need research to better understand the late effects of cancer treatment and to develop evidence-based recommendations on the performance and, especially, the periodicity, of surveillance for recurrence as well as monitoring for second cancers and/or late effects of treatment. Second, we need rigorous evaluation of existing and newly designed models for delivering comprehensive care to cancer survivors. Third, we need to educate and train all levels of medical providers in cancer survivorship.

This supplement begins to cover many of these concepts and expands the breadth of knowledge of cancer survivorship across research, education and clinical practice. Primary care providers need not have expertise in cancer survivorship, but they do need to recognize the potential symptoms, begin the evaluation and, if needed, refer for expert consultation. Several papers describe common manifestations of treatment that general internists need to be aware of, such as bone loss and joint pain among breast cancer survivors treated with adjuvant aromatase inhibitors (Hong); bone loss, obesity and hyperlipidemia among prostate cancer survivors treated with androgen deprivation therapy (Saylor); and congestive heart failure, avascular necrosis and obesity among adult survivors of multimodal therapy for childhood cancer (Armenian). The latter study provides an intriguing exploration about the role of genetics in the late manifestations of treatment. In sharing her personal story, Dr. Bishop elegantly reflects on the medical sequalae she experienced decades after lymphoma treatment.

A number of articles address the dimensions of cancer survivorship that intersect the medical and psychosocial domains, including contraception (Schwartz), sexual dysfunction (Park), fatigue (Manzullo) and depression (Fann). The latter study showed that a multidisciplinary intervention had marked effects on improving depressive symptoms among cancer survivors. The complex psychosocial aspects in cancer survivorship are evident in the personal reflections of a researcher and a survivor (Blank) and a general internist who guided her father through difficult treatment decisions (Duffy), and in the intriguing study exploring self-identity after cancer (Park). Though we sometimes give less attention to these dimensions of care to our general medical population, few would dispute their importance. With training and guidance, we can adequately address these issues among cancer survivors.

Finally, cancer survivors may face financial burdens associated with the high cost of treatment and surveillance as well as loss of employment and/or insurance. Primary care provi- 
ders, who often have ongoing and long-lasting relationships with patients, need to be aware of these issues and address the effects of cancer on employment (Norredam) and costs related to long-term cancer medications (Pezzin).

Several articles raise questions about the models of care for cancer survivors and the role of care summaries in the transition from oncology to primary care. Goytia describes a newly created comprehensive clinical service integrated within a public hospital cancer center; Gusani describes a multidisciplinary gastrointestinal cancer survivorship clinic. Kantsiper and Burg use qualitative methodologies to address the difficulties faced by breast cancer survivors in their transition to survivorship and point to the limitations in the current care summaries, particularly for minority populations. While many cancer survivors see their oncologists more often than primary care providers, they expect a focus on prevention from the latter (Haggstrom). Findings from Coups and Hudson suggest that we can do better at providing smoking cessation counseling and cancer screening to cancer survivors. Interestingly, Miller proposes that survivorship spans the continuum of cancer, and in each phase, general internists have an opportunity to provide comprehensive patient-centered care.

Clearly, we can not advise cancer survivors to transition to primary care settings without acknowledging the need for education and training of general internists in cancer survivorship. Uijtdehaage et al. present a framework for a cancer survivorship curriculum that was implemented at the medical school level, and Potter points to potential directions for cancer survivorship education. A perspective by Hong raises a question about certification for general internists in cancer survivorship. While all primary care physicians need to have better knowledge and skill in cancer survivorship, Hong suggests that an accredited certification may be the future for generalists who seek expertise in cancer survivorship. As science evolves, the American Board of Internal Medicine should include questions about cancer survivorship in its certification process. Modules on cancer survivorship care for those seeking recertification might be a good way to provide both certification and training to internists. Whether a separate certification should be available for general internists who pursue expertise in any area, including cancer survivorship, needs further debate and exploration.

While this supplement fills an important gap in the area of cancer survivorship care for the general internist and lays the groundwork for improving the care for cancer survivors in general medicine research, teaching and clinical practice, there is more to be done. First, we need to continue to monitor cancer survivors for late effects of treatment and develop tools that may be used in clinical practice to anticipate, recognize and evaluate potential manifestations. Generalist health services researchers have long been evaluating guidelines, assessment tools and screening instruments and the utility of reminders in the management of hypertension, diabetes and other chronic medical conditions. This work can be extended to cancer survivorship. Second, generalists can work with oncologists to improve transitions of care, evaluate care models and develop comprehensive care summaries that include the relevant elements needed for primary care practice. Researchers can test the acceptance of such summaries by patients and primary care providers and their effects on outcomes of care, including quality and costs. Comparative effectiveness research may be an appropriate direction for this line of inquiry. ${ }^{12}$ Finally, generalist educators need to enhance their awareness of cancer survivorship and its implications on primary care, expose the field to medical students and residents, and integrate cancer survivorship in education and training curricula.

Corresponding Author: Larissa Nekhlyudov, MD, MPH; Department of Population Medicine, Harvard Medical School, 133 Brookline Avenue, 6th Floor, Boston, MA 02215, USA (e-mail: Larissa Nekhlyudov@vmed.org).

\section{REFERENCES}

1. Institute of Medicine and National Research Council of the National Academies. From Cancer Patient to Cancer Survivor: Lost in Transition. Washington, D.C.: The National Academies Press; 2006.

2. Larson EB, Fihn SD, Kirk LM, Levinson W, Loge RV, Reynolds E, et al. The future of general internal medicine. Report and recommendations from the Society of General Internal Medicine (SGIM) task force on the domain of general internal medicine. J Gen Intern Med. 2004;19:69-77.

3. Grunfeld E, Mant D, Vessey MP, Fitzpatrick R. Specialist and general practice views on routine follow-up of breast cancer patients in general practice. Fam Pract. 1995; 12:60-5.

4. Nissen MJ, Beran MS, Lee MW, Mehta SR, Pine DA, Swenson KK. Views of primary care providers on follow-up care of cancer patients. Fam Med. 2007;39:477-82.

5. Snyder CF, Earle CC, Herbert RJ, Neville BA, Blackford AL, Frick KD. Trends in follow-up and preventive care for colorectal cancer survivors. J Gen Intern Med. 2008;23:254-9.

6. Earle CC, Burstein HJ, Winer EP, Weeks JC. Quality of non-breast cancer health maintenance among elderly breast cancer survivors. J Clin Oncol. 2003;21(8):1447-51.

7. Snyder CF, Earle CC, Herbert RJ, Neville BA, Blackford AL, Frick KD. Preventive care for colorectal cancer survivors: a 5-year longitudinal study. J Clin Oncol. 2008;26:1073-9.

8. Snyder CF, Frick KD, Kantsiper ME, Peairs KS, Herbert RJ, Blackford AL, et al. Prevention, screening, and surveillance care for breast cancer survivors compared with controls: changes from 1998 to 2002 . J Clin Oncol. 2009;27:1054-61.

9. Earle CC, Neville BA. Under use of necessary care among cancer survivors. Cancer. 2004;101:1712-9.

10. Cheung WY, Neville BA, Cameron DB, Cook EF, Earle CC. Comparisons of patient and physician expectations for cancer survivorship care. J Clin Oncol. 2009;27(15):2489-95.

11. Nekhlyudov L. "Doc, should I see you or my oncologist?" A primary care perspective on opportunities and challenges in providing comprehensive care for cancer survivors. J Clin Oncol. 2009;27(15):2424-6.

12. Sox HC, Greenfield S. Comparative effectiveness research: a report from the Institute of Medicine. Annals Intern Med. 2009;151.

Acknowledgements We thank the members of the SGIM Cancer Research Interest Group who served as the Editorial Board for this supplement, including Drs. Nancy Keating, Alton Hart, Claire Snyder, David Haggstrom, Pamela Ganschow, and Jennifer Potter, as well as the numerous external reviewers who provided us with helpful comments. We also thank the Lance Armstrong Foundation for providing funding support.

Larissa Nekhlyudov, MD, MPH, JGIM Supplement Guest Editor

Lori Bastian, MD, MPH, JGIM Deputy Editor

Jeffrey Jackson, MD, MPH, JGIM Deputy Editor 